\title{
Biofuel Cells and Inductive Powering as Energy Harvesting Techniques for Implantable Sensors
}

\author{
Jacopo Olivo*, Sandro Carrara, and Giovanni De Micheli \\ Integrated Systems Laboratory, École Polytechnique Fédérale de Lausanne - EPFL, Lausanne, 1015, Switzerland
}

\begin{abstract}
In order to increase the power autonomy of implantable sensors, energy harvesters can aid and, in certain cases, substitute implantable batteries. The paper describes two promising techniques among the approaches presented in literature: biofuel cells and inductive powering. For both techniques, key points and drawbacks are illustrated, together with a summary of the solutions presented in literature. Potential methods to enhance the performance of biofuel cells by means of nanostructured materials are presented and discussed.
\end{abstract}

Keywords: Energy Harvesting, Biofuel Cells, Inductive Powering, Implantable Sensors.

\section{CONTENTS}

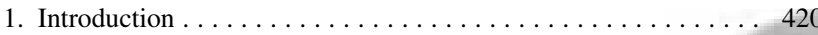

2. Glucose Fuel Cells $\ldots \ldots \ldots \ldots \ldots \ldots \ldots \ldots \ldots \ldots \ldots \ldots \ldots 420$

3. Biofuel Cells Exploiting Nanostructured Materials . . . . . . . . 422

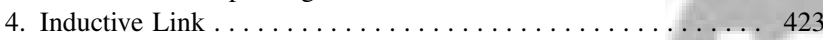

5. Comparison ....................... 423

Acknowledgments . . . . . . . . . . . . . . . . . 424

References and Notes ... . . . . . . . . . . . . . . . . 424

\section{INTRODUCTION}

Nowadays the field of implantable biosensors has attracted the interest of academia and industry. The possibility of real-time monitoring of the human body from inside paves the way to a great number of applications and offers wide scenarios for the future. Several requirements must be addressed to realize these scenarios: implantable biosensors should be minimally invasive and with a large power autonomy. This latter requirement can be achieved by means of energy harvesters. These devices exploit natural or artificial power sources surrounding the person to assist the implanted batteries and, in certain cases, to completely eliminate the need for using these batteries. Energy harvesters for implantable biosensors have been exhaustively studied and a large number of solutions for different cases can be found in literature. ${ }^{1}$

The use of fuel cells exploiting chemical species present into the body fluids to harvest energy for implantable biosensors offers considerable advantages. Indeed, the constant availability of the reactants directly into the body makes external recharging mechanisms or battery

*Author to whom correspondence should be addressed. replacement unnecessary. Biofuel cells exploiting the oxidation of the glucose contained into the body fluids have been studied since the 1960's. ${ }^{2}$ In Section 2, some solutions presented in the literature are reported.

The possibility to improve the performance of implantable fuel cells by means of nanostructured materials is discussed in Section 3. The approach is based on the solutions used with no-biological fuel cells, thus obtaining a sensible improvement of the furnished power.

Another option to power implanted biosensors, widely explored in the last two decades, is remote powering by means of inductive links. Such a technique utilizes an external power source to induce a flow of current into an implanted inductor by means of a current flowing into an external inductor. The main advantage of using this technique is the possibility to communicate bidirectionally with the implanted device without any embedded RF transmitter. This is due to the possibility to modulate the load of the implanted biosensor and to detect the effects of such operation on the current flowing on the external inductor. This method is often named "backscattering". In Section 4, some examples are reported and discussed.

Finally, Section 5 concludes the paper with a comparison in terms of furnished power and lifetime between the two different techniques described.

\section{GLUCOSE FUEL CELLS}

A fuel cell is an electrochemical device that generates current through the reaction of two chemical species flowing into it. The use of fuel cells capable to harvest energy directly from the body fluids has considerable advantages in the field of implantable biosensors. Indeed, the constant 
presence and availability of the reactants directly into the body makes unnecessary external recharging mechanisms or replacement.

Implantable fuel cells using glucose as reactant are probably the most explored biofuel cells, due to the high availability of glucose into the body fluids. An interesting review in this area has been done by Kerzenmacher et al. ${ }^{3}$ Glucose fuel cells can be grouped into three broad categories, depending on the catalyst used to enable the reaction: enzymatic, microbial, and abiotic.
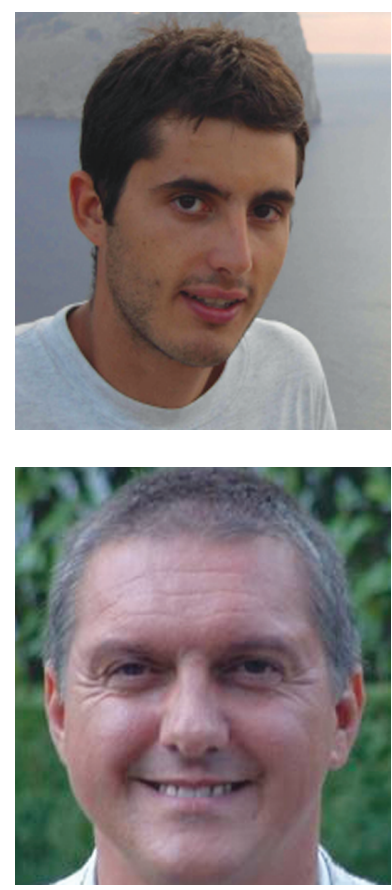

Jacopo Olivo received the M.Sc. with honors in electrical engineering from the University of Bologna (Italy) in 2008. He approached the field of biosensors during his master project, concerning the design and development of an integrable system for electrochemical measurements in point-of-care applications for personalized medicine. Starting from September 2009, he is a research assistant and doctoral candidate in the Integrated System Laboratory at the EPFL (Switzerland). His actual research interest is focused on energy scavenging techniques for implantable biosensors.

Sandro Carrara graduated in Electronics in Technical school of Albenga, he received a Master in Physics from Genoa University and his Ph.D. in Biochemistry and Biophysics from Padua University. His main scientific interest is on electrical phenomena mediated by nano-structured molecular thin-films. He currently has a special focus on development of protein and DNA based CMOS chips. He has more than 80 international publications and 10 patents. In 1996, he won a NATO Advanced Research prize for his original contribution on the role of nano-particles size in single-electron conductivity. More recently, he was awarded at the NanoEurope Symposium in 2009 (Rapperswil), and at the IEEE International Conference PRIME with the bronze leaf medal (2010-Berlin) and the golden leaf medal (2009-Cork). From 1997 to 2000, he was member of an international committee at the ELETTRA Synchrotron. From 2000 to 2003, he was scientific leader of a National Research Program (PNR) in the field of Nanobiotechnology. In 2006, he received the best 2006 referees' award from Biosensor and Bioelectronics journal. He is an Associate Editor of the IEEE Transactions on Biomedical Circuits and Systems and of the Sensors Journals. He is referee of other eleven international journals. He is an internationally esteemed expert of the evaluation panel of the Academy of Finland in a research program for the years 2010-2013. He is in the Board of the IEEE international conference on Biomedical Circuits and Systems (Beijing, 2009; Cyprus, 2010). He also is the Chair of a Workshop on Nano-Bio-Sensing paradigms and applications (Luzern, 2009) and Technical Program Co-Chair of the International Symposium on Medical Information and Communication Technology (Montreux, 2011). He has been Professor in Biophysics at University of Genoa and in Nanobiotechnology at University of Bologna. He is currently Scientist and Lecturer at EPFL. He also is Professor of nano-bio-sensing and micro/nano interfaces at University of Genoa.

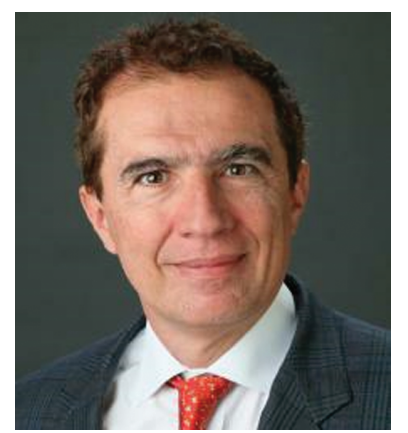

Giovanni De Micheli is Professor and Director of the Institute of Electrical Engineering and of the Integrated Systems Centre at EPF Lausanne, Switzerland. He is program leader of the Nano-Tera.ch program. His research interests include several aspects of design technologies for integrated circuits and systems, such as synthesis for emerging technologies, networks on chips and 3D integration. He is also interested in heterogeneous platform design including electrical components and biosensors, as well as in data processing of biomedical information. Prof. De Micheli is the recipient of the 2003 IEEE Emanuel Piore Award for contributions to computer-aided synthesis of digital systems. He is a Fellow of ACM and IEEE. He received the Golden Jubilee Medal for outstanding contributions to the IEEE CAS Society in 2000. He received the 1987 D. Pederson Award for the best paper on the IEEE Transactions on CAD/ICAS, two Best Paper Awards at the Design Automation Conference, in 1983 and in 1993, and a Best Paper Award at the DATE Conference in 2005. He has been serving IEEE in several capacities, namely: Division 1 Director (2008-9), co-founder and President Elect of the IEEE Council on EDA (2005-7), President of the IEEE CAS Society (2003), Editor in Chief of the IEEE Transactions on CAD/ICAS (1987-2001). He is and has been Chair of several conferences, including DATE (2010), pHealth (2006), VLSI SOC (2006), DAC (2000) and ICCD (1989). 
Enzymatic glucose fuel cells use enzymes, such as glucose oxidase or laccase, as catalysts to enable the electrode reactions. ${ }^{4}$ The examples reported in the literature show a fair value of power density, up to $430 \mu \mathrm{W} / \mathrm{cm}^{2}{ }^{5}$ The main issue of these devices is the lifetime of the enzyme. Indeed, the lifetime of their enzymatic catalyst does not exceed the period of 1 month. ${ }^{6}$ However, a glucose sensor based on glucose oxidase recently presented in literature ${ }^{7}$ has been able to operate for more than 1 year. The long lifetime of the glucose oxidase used by Ref. [7] shows the possibility to have enzymatically catalyzed fuel cells with an extended lifetime.

Glucose fuel cells abiotically catalyzed utilize nonbiological catalysts, such as noble metals or activated carbon, to induce the reaction. This family of fuel cells has been studied since the 1960 's. ${ }^{2}$ Besides the long-term stability, these devices have good sterilizability and biocompatibility, due to the use of noble metals as catalysts. A schematic example of an abiotically catalyzed fuel cell working with glucose is reported in Figure 1. In that example, glucose $\left(\mathrm{C}_{6} \mathrm{H}_{12} \mathrm{O}_{6}\right)$ is oxidized on the anode site, thus generating gluconic acid $\left(\mathrm{C}_{6} \mathrm{H}_{12} \mathrm{O}_{7}\right)$ and protons, These protons cross the conducting membrane and reach the cathode to reduce the oxygen. The electrons obtained by means of the oxidation are used to generate power.

In Ref. [3] the state of the art of glucose fuel cells abiotically catalyzed is reported. During in vitro experiments, glucose fuel cells abiotically catalyzed have generated up to $50 \mu \mathrm{W} / \mathrm{cm}^{2} .^{8}$ Experiments in vivo, performed on a dog, have generated $2.2 \mu \mathrm{W} / \mathrm{cm}^{2}$ over a period of 30 days. $^{9}$ Finally, Ref. [10] proposed an abiotically catalyzed glucose fuel cell that operates in tissue rather than in blood stream. Since oxygen and glucose are both dissolved into interstitial fluids, it is difficult in that case to oxidase glucose without, simultaneously, reducing oxygen

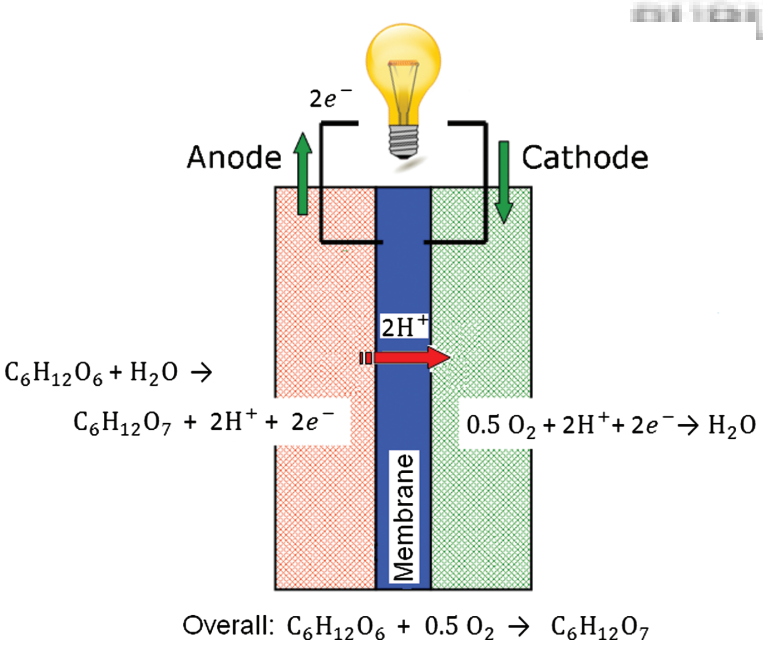

Fig. 1. Schematic representation of an abiotically catalyzed glucoseoxygen fuel cell. Glucose $\left(\mathrm{C}_{6} \mathrm{H}_{12} \mathrm{O}_{6}\right)$ is oxidized on the anode, thus generating gluconic acid $\left(\mathrm{C}_{6} \mathrm{H}_{12} \mathrm{O}_{7}\right)$ and protons. These protons cross the conducting membrane and reach the cathode to reduce the oxygen. ${ }^{3}$
If combined, these two reactions generate an electrochemical short-circuit that compromises the correct functioning of the device. To mitigate this drawback, Ref. [10] proposed to reduce the oxygen into an outer oxygen-selective cathode. Thus, an anoxic region is generated inside the fuel cell and the glucose can be oxidized. The device presented by Ref. [10] can operate for 224 days. The power generated in the beginning of this time period was $3.3 \mu \mathrm{W} / \mathrm{cm}^{2}$, with an open-circuit voltage of $337 \mathrm{mV}$; the power generated at the end of the experiment was $1 \mu \mathrm{W} / \mathrm{cm}^{2}$, with an open-circuit voltage of $241 \mathrm{mV}$. The loss in terms of generated power during the whole experiment is about $70 \%$. The authors assume that the performance degradation could be due to the decrease in the open-circuit voltage.

Another degradation factor of glucose fuel cells is the separator membrane between the electrodes. The aim of this element is to separate the electrodes, by preventing the electrons from crossing it and by allowing only the protons to reach the other side. The separator membrane is a fundamental element and its degradation can compromise the functioning of the fuel cell. Different kinds of separator membranes are reported in Ref. [3]. However, enzymatic glucose fuel cells that operate without membrane (membrane-less) have been demonstrated. ${ }^{11,12}$

Finally, in microbial fuel cells the enzymatic system of an electro-active micro-organism is used to enable the electrode reaction. However, due to risks of infection related to the use of most known micro-organisms, the development of this kind of biofuel cells has been lower than the other two types.

\section{BIOFUEL CELLS EXPLOITING NANOSTRUCTURED MATERIALS}

As reported in the previous section, enzymatically and abiotically catalyzed fuel cells are the most commonly used for implantable devices.

Fuel cells based on biological catalysts, such as the enzymes, typically have a short lifetime due to the limited life-cycle of their biological elements. However, experiments conducted in vivo have recently shown that glucose oxidase can maintain the right properties for a long time period. Indeed, devices based on glucose oxidase have exhibited appreciable performance over periods of $4^{13}$ and 12 months.?

Abiotically catalyzed fuel cells generally have a longer lifetime, due to the absence of biological catalysts. As reported in Section 2, a lifetime of several months has been shown for this kind of fuel cells. ${ }^{10}$ However, the amount of power delivered by these devices is quite lower than the power provided by enzymatically catalyzed fuel cells.

As reported in the previous section, experiments performed in vivo with abiotically catalyzed fuel cells have generated a power of $2.2 \mu \mathrm{W} / \mathrm{cm}^{2}{ }^{9}$. This value is not sufficient for implantable sensors to monitor the human 
metabolism. As an example, the sensor presented in Ref. [14] requires $32 \mu W$ for the molecular detection, $2.5 \mu \mathrm{W}$ for the $\mathrm{pH}$ measurement, and $1.4 \mu \mathrm{W}$ to control the temperature sensor. Furthermore, $12 \mu \mathrm{W}$ are needed to multiplex and read all these measurements.

In order to increase the performance of abiotically catalyzed fuel cells, proton exchange membranes have been developed by using carbon nanotubes directly grown on carbon paper by means of chemical vapor deposition, ${ }^{15}$ or by using carbon nano-fibers ${ }^{16}$ to support the proton exchange. Nano-particles of titanium oxide have also been used to improve proton exchange membranes. ${ }^{17}$ Improved nano-structured $\mathrm{Pt}-\mathrm{Fe} / \mathrm{C}$ has been tested as cathode catalyst in methanol fuel cells. ${ }^{18}$ All these experiments have been performed within a temperature range from $70{ }^{\circ} \mathrm{C}$ to $90{ }^{\circ} \mathrm{C}$, that is not suitable for in-body operations. However, similar improvements have also been obtained at room temperature by using nanoparticulated gold-electrodes. ${ }^{19}$

Finally, nano-structured materials assure improved layering phenomena. ${ }^{20}$ In the last five years, devices based on glucose oxidase have demonstrated better performance by using carbon nanotubes, ${ }^{21-23}$ metallic nanoparticles, ${ }^{24-27}$ or prussian blue nano-cluster. ${ }^{28}$ In the field of fuel cells, carbon nanotubes have already been used to increase the performance of such devices. ${ }^{29-32}$ In particular, Ref. [31] has achieved a power of $760 \mu \mathrm{W} / \mathrm{cm}^{2}$ for one week by using DNA-wrapped single walled carbon nanotubes.

Due to the toxicity of nanoparticles in general, and in particular of the carbon nanotubes, ${ }^{33,34}$ it is necessary to use a selective membrane in order to allow reactants to flow into the cell without permitting nanoparticles to flow out of the device. Carbon nanotubes typically have a length in the range between $500 \mathrm{~nm}$ and $5 \mu \mathrm{m}$ and a width in the range between $2 \mathrm{~nm}$ and $70 \mathrm{~nm}$; thus, since glucose molecules are smaller than $1 \mathrm{~nm}$, a membrane with a cutoff size of few nanometers can allow glucose molecules to penetrate and prevent carbon nanotubes from diffusing into the body.

\section{INDUCTIVE LINK}

As mentioned in the Introduction, inductive links are a well-suited solution for implanted biosensors due to the possibility to perform bidirectional data communication without any implanted RF transmitter. Furthermore, the small form factor makes these links compatible with lowinvasive body implantations.

The simplest inductive link consists of two magnetically-coupled inductors. A power amplifier, typically operating in class $\mathrm{E}$, drives an alternate current into the inductor placed outside of the body. Thus, a current is induced to flow into the implanted inductor. Downlink transmission from the external devices to the implanted biosensors can be achieved by modulating the power signal generated by the class-E amplifier. Amplitude Shift Keying (ASK) is often used due to the simplicity of the demodulator. However, by modifying the amplitude of the power signal, the transmission efficiency becomes sub-optimal. Furthermore, data transmission rate is lower as compared with other kinds of downlink modulations. Another solution for the downlink communication is the Frequency Shift Keying (FSK). FSK permits to reach higher transmission rates if compared with the ASK, but it needs a more complex demodulator and the difficulty of synchronization between transmitter and receiver is increased. ${ }^{35}$ Uplink transmission is commonly achieved by means of the Load Shift Keying (LSK). By modifying the impedance of the secondary circuit, the load seen by the primary circuit consequently varies, causing the current flowing on the primary coil to change. This change can be detected by an external demodulator, enabling the uplink transmission without any internal RF transmitter. A schematic representation of an inductive link is shown in Figure 2.

In our previous work, ${ }^{1}$ we have reported several results presented in literature, summarized in Table I. As shown by these data, this technique can provide a fair amount of power, up to few milliwatts, over a distance that spans from few millimeters up to few centimeters.

Inductive powering is already used in some commercial products available on the market. "RestoreUltra," 36 produced by Medtronic, is a stimulator of the spinal cord and is equipped with a battery that can be recharged from outside by using inductive powering, thus avoiding invasive surgery.

\section{COMPARISON}

In the previous sections we have introduced and analyzed two different harvesting techniques to power implanted

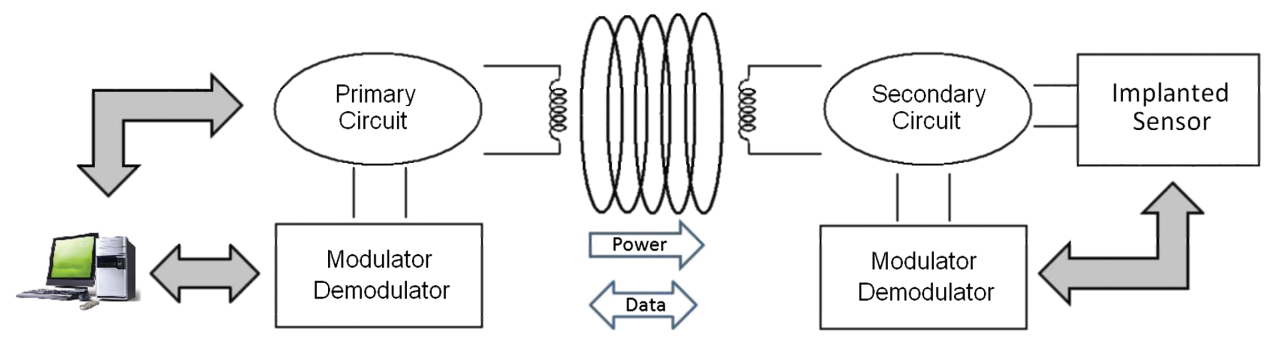

Fig. 2. Schematic representation of an inductive link performing remote powering and bidirectional data transmission. 
Table I. Implantable devices exploiting inductive links for wireless power transmission. ${ }^{1}$

\begin{tabular}{|c|c|c|c|c|c|c|c|}
\hline Ref. & $\begin{array}{c}\text { Coil area } \\
\left(\lambda=10 \mathrm{~mm}^{2}\right)\end{array}$ & $\begin{array}{l}\text { Coil thickness } \\
(\sigma=1 \mathrm{~mm})\end{array}$ & $\begin{array}{l}\text { Carrier } \\
\text { frequency }\end{array}$ & $\begin{array}{c}\text { Data } \\
\text { transmission }\end{array}$ & Bit rate & $\begin{array}{c}\text { Power } \\
\text { consumption }\end{array}$ & Distance \\
\hline [37] & $\begin{array}{l}\text { Tx: } 7.8 \lambda \\
\text { Rx: } 1.7 \lambda\end{array}$ & $\begin{array}{c}\text { Tx: } 2 \sigma \\
\text { Rx: } 2.5 \sigma\end{array}$ & $4 \mathrm{MHz}$ & $\begin{array}{c}\text { Downlink: PWM-ASK } \\
\text { Uplink: LSK }\end{array}$ & Uplink: $125 \mathrm{kbps}$ & $90 \mathrm{~mW}^{a}$ & $5 \mathrm{~mm}$ \\
\hline [38] & $\begin{array}{l}\text { Tx: } 196 \lambda \\
\text { Rx: } 31.4 \lambda\end{array}$ & $\begin{array}{l}\text { Tx: } 9.5 \sigma \\
\mathrm{Rx}: 5 \sigma\end{array}$ & $4 \mathrm{MHz}$ & Uplink: LSK & Uplink: $5 \div 10 \mathrm{kbps}$ & $11 \mathrm{~mW}^{b}$ & $28 \mathrm{~mm}$ \\
\hline [39] & $\begin{array}{l}\text { Tx: } 13200 \lambda \\
\text { Rx: } 7.9 \lambda\end{array}$ & $\begin{array}{l}\text { Tx: } 300 \sigma \\
\text { Rx: } 13 \sigma\end{array}$ & $1 \mathrm{MHz}$ & & & $150 \mathrm{~mW}^{b}$ & $205 \mathrm{~mm}$ \\
\hline [40] & $\mathrm{Rx}: 10 \lambda$ & Rx: $0.035 \sigma$ & $1 \mathrm{MHz}$ & & & $10 \mathrm{~mW}^{b}$ & $5 \mathrm{~mm}$ \\
\hline [41] & $\begin{array}{l}\text { Tx: } 283 \lambda \\
\text { Rx: } 31.4 \lambda\end{array}$ & & $0.7 \mathrm{MHz}$ & $\begin{array}{l}\text { Downlink: ASK } \\
\text { Uplink: LSK }\end{array}$ & $\begin{array}{l}\text { Downlink: } 60 \mathrm{kbps} \\
\text { Uplink: } 60 \mathrm{kbps}\end{array}$ & $50 \mathrm{~mW}^{b}$ & $30 \mathrm{~mm}$ \\
\hline [42] & $\begin{array}{l}\text { Tx: } 31.4 \lambda \\
\operatorname{Rx}: 7.9 \lambda\end{array}$ & & $10 \mathrm{MHz}$ & $\begin{array}{l}\text { Downlink: ASK } \\
\text { Uplink: BPSK }\end{array}$ & $\begin{array}{l}\text { Downlink: } 120 \mathrm{kbps} \\
\text { Uplink: } 234 \mathrm{kbps}\end{array}$ & $\begin{array}{l}22.5 \mathrm{~mW} \text { in vitro }{ }^{b} \\
\approx 19 \mathrm{~mW} \text { in vivo }{ }^{b}\end{array}$ & $15 \mathrm{~mm}$ \\
\hline [43] & $\begin{array}{c}\text { Tx: } 196.3 \lambda \\
\text { Rx: } 3.5 \lambda\end{array}$ & $\begin{array}{l}\text { Tx: } 5 \sigma \\
\operatorname{Rx}: 1.9 \sigma\end{array}$ & $5 \mathrm{MHz}$ & Downlink: OOK & Downlink: $100 \mathrm{kbps}$ & $\approx 5 \div 10 \mathrm{~mW}^{a}$ & $40 \mathrm{~mm}$ \\
\hline [44] & Rx: $112.5 \lambda$ & $\mathrm{Rx}: 10 \sigma$ & $6.78 \mathrm{MHz}$ & $\begin{array}{l}\text { Downlink: OOK } \\
\text { Uplink: LSK }\end{array}$ & Uplink: 200 kbps & $120 \mathrm{~mW}^{a}$ & $25 \mathrm{~mm}$ \\
\hline [45] & $\begin{array}{l}\text { Tx: } 152 \lambda \\
\operatorname{Rx}: 3.2 \lambda\end{array}$ & $\mathrm{Rx}: 1 \sigma$ & $13.56 \mathrm{MHz}$ & Uplink: LSK & & $0.198 \mathrm{~mW}^{b}$ & $40 \mathrm{~mm}$ \\
\hline [46] & $\begin{array}{l}\text { Tx: } 40 \lambda \\
\text { Rx: } 0.4 \lambda\end{array}$ & $\begin{array}{l}\text { Tx: } 0.038 \sigma \\
\text { Rx: } 0.038 \sigma\end{array}$ & $\begin{array}{r}915 \mathrm{MHz} \\
\mathrm{De}\end{array}$ & ared by Ingenta & & $0.14 \mathrm{~mW}^{b}$ & $15 \mathrm{~mm}$ \\
\hline
\end{tabular}

${ }^{a}$ Power consumed by the implantable sensor. ${ }^{b}$ Power effectively supplied by the inductive link.

\section{Thu, 28 Jul $201108: 57: 41$}

biosensors. Biofuel cells, presented in Section 2, can harvest energy from body fluids. Theoretically, these cells can continuously operate as the fluids are supplied. Practically, degradation of the components and limited operation-time of the enzymes in the case of enzymatically catalyzed fuel cells, limit their lifetime. However, examples of enzymes with a lifetime of 1 year have recently been reported in the literature. ${ }^{7}$ Thus, the use of such enzymes for enzymatically catalyzed fuel cells can constitute a noticeable improvement.

Abiotically catalyzed fuel cells do not use enzymes to enable the reactions, thus their lifetime is generally higher. However, these cells can generate a smaller amount of energy if compared with enzymatically catalyzed fuel cells.

In both cases, these devices do not require any external power source and can harvest energy autonomously. As previously reported, glucose fuel cells abiotically catalyzed can provide a power of $2.2 \mu \mathrm{W} / \mathrm{cm}^{2}$ during experiments performed in vivo. ${ }^{9}$ Instead, enzymatically catalyzed fuel cells can generate up to $760 \mu \mathrm{W} / \mathrm{cm}^{2}$ with the use of carbon nanotubes. ${ }^{31}$

Inductive links, introduced in Section 4, can generally provide power in the order of few milliwatts. Moreover, inductive links enable bidirectional data communication without using any implanted RF transmitter. Finally, the performance of these links is not degraded due to the absence of moving parts and the lack of interaction with body fluids. However, these devices need an external power source to operate.

The size and shape of the external power source strongly depend on the requirements of the implanted device. For example, the transmitting coil used by Ref. [39] has an area of $0.132 \mathrm{~m}^{2}$ and a thickness of $0.3 \mathrm{~m}$, and has been designed to surround the patient. Thus, the high power provided, up to $150 \mathrm{~mW}$, is obtained at the expense of the wearability of the transmitter coil. However, other examples reported in Table I use easily-wearable, smaller transmitter inductors. Finally, printed inductors can be embedded into patches located just over the implantation areas. The amount of power provided by these devices is generally sufficient for biosensors performing complex operations, such as the monitoring of human metabolism. As an example, the device presented in Ref. [14] has a total power consumption of about $48 \mu \mathrm{W}$.

- These two techniques offer completely different key points and drawbacks. For low-invasive, not deeplyimplanted devices that perform complex operations, such as the analysis of the human metabolism, inductive links can provide an appreciable amount of power with a low discomfort of the patient and without loss of performance. Moreover, this technique has already reached the market with commercially-available devices. ${ }^{36}$ Biofuel cells still present some strong drawbacks that limit their efficiency in terms of furnished power. However, this solution can provide power continuously without any external amplifier and research efforts aim at improving the performance of such devices. In this sense, nanostructuration techniques presented in Section 3 represent a promising solution to obtain a higher power efficiency.

Acknowledgments: The research work presented in this paper was funded by the i-IronIC project and by the NanoSys project. The NanoSys project is within the program ERC-2009-AdG-246810, the i-IronIC project was financed with a grant from the Swiss Nano-Tera.ch initiative and evaluated by the Swiss National Science Foundation. 


\section{References and Notes}

1. J. Olivo, S. Carrara, and G. De Micheli, IEEE Sensors Journal (2010), in press.

2. S. Wolfson, Jr., S. K. Gofberg, P. Prusiner, and L. Nanis, Transactions-American Society for Artificial Internal Organs 14, 198 (1968)

3. S. Kerzenmacher, J. Ducre, R. Zengerle, and F. von Stetten, Journal of Power Sources 182, 1 (2008).

4. S. C. Barton, J. Gallaway, and P. Atanassov, Chemical Reviews 104, 4867 (2004).

5. N. Mano, F. Mao, and A. Heller, J. Am. Chem. Soc. 125, 6588 $\underline{(2003)}$.

6. R. A. Bullen, T. C. Arnot, J. B. Lakeman, and F. C. Walsh, Biosens. Bioelectron. 21, 2015 (2006).

7. D. A. Gough, L. S. Kumosa, T. L. Routh, J. T. Lin, and J. Y. Lucisano, Science Translational Medicine 2, 42 (2010).

8. P. Malachesky, G. Holleck, F. McGovern, and R. Devarakonda, Parametric studies of implantable fuel cell, Proceedings of the 7th Intersociety Energy Conversion Engineering Conference (1972), pp. 727-732.

9. R. F. Drake, B. K. Kusserow, S. Messinger, and S. Matsuda, ASAIO Journal 16, 199 (1970).

10. S. Kerzenmacher, J. Ducrée, R. Zengerle, and F. von Stetten, Journal of Power Sources 182, 66 (2008).

11. F. Barrière, P. Kavanagh, and D. Leech, Electrochimica Acta 51, 5187 (2006).

12. L. Brunel, J. Denele, K. Servat, K. B. Kokoh, C. Jolivalt, C. Innocent, M. Cretin, M. Rolland, and S. Tingry, Electrochem. Commun. 9, 331 (2007).

13. B. Yu, N. Long, Y. Moussy, and F. Moussy, Biosens. Bioelectron. 21, 2275 (2006).

14. S. Carrara, M. D. Torre, A. Cavallini, D. De Venuto, and G. De Micheli, Multiplexing $\mathrm{pH}$ and temperature in a molecular biosensor, IEEE Biomedical Circuits and Systems Conference (2010), pp. $146-149$.

15. C. Wang, M. Waje, X. Wang, J. M. Tang, R. C. Haddon, and Y. Yan, Nano Lett. 4, 345 (2004).

16. A. M. Kannan and L. Munukutla, J. Power Sources 167, 330 (2007).

17. N. Rajalakshmi, N. Lakshmi, and K. S. Dhathathreyan, International Journal of Hydrogen Energy 33, 7521 (2008).

18. W. Li, W. Zhou, H. Li, Z. Zhou, B. Zhou, G. Sun, and Q. Xin, Electrochemical Acta 49, 1045 (2004).

19. F. A. Coowar, G. Vitins, G. O. Mepsted, S. C. Waring, and J. A Horsfall, J. Power Sources 175, 317 (2008).

20. S. Carrara, V. Bavastrello, D. Ricci, E. Stura, and C. Nicolini, Sens. Actuators, B: Chem. 109, 221 (2005).

21. M. Tsai and Y. Tsai, Sens. Actuators, B: Chem. 141, 592 (2009).

22. C. Deng, J. Chen, X. Chen, C. Xiao, L. Nie, and S. Yao, Biosens. Bioelectron. 23, 1272 (2008).

23. C. Boero, S. Carrara, G. Del Vecchio, D. Albini, L. Calzá, and G. De Micheli, Carbon nanotubes-based electrochemical sensing for cell culture monitoring, IEEE International Conference on Complex Medical Engineering (2010), pp. 288-293.

24. S. Zhao, K. Zhang, Y. Bai, W. Yang, and C. Sun, Bioelectrochemistry 69, 158 (2006)
25. A. Ramanaviciene, G. Nastajute, V. Snitka, A. Kausaite, N. German, D. Barauskas-Memenas, and A. Ramanavicius, Sens. Actuators, B: Chem. 137, 483 (2009).

26. H. Wang, X. Wang, X. Zhang, X. Qin, Z. Zhao, Z. Miao, N. Huang, and Q. Chen, Biosens. Bioelectron. 25, 142 (2009).

27. S. Carrara, C. Boero, and G. De Micheli, Quantum dots and wires to improve enzyme-based electrochemical bio-sensing, Proceedings of the 4th International Conference Nano-Nets (2009), pp. 189-199.

28. H. Ohnuki, T. Saiki, A. Kusakari, M. Ichihara, and M. Izumi, Thin Solid Films 516, 8860 (2008)

29. C. Yu, M. Yen, and L. Chen, Biosens. Bioelectron. 25, 2515 (2010).

30. A. Vaze, N. Hussain, C. Tang, D. Leech, and J. Rusling, Electrochem. Commun. 11, 2004 (2009).

31. J. Y. Lee, H. Y. Shin, S. W. Kang, C. Park, and S. W. Kim, Biosens. Bioelectron. 26, 2685 (2011).

32. D. Ivnitski, B. Branch, P. Atanassov, and C. Apblett, Electrochem. Commun. 8, 1204 (2006).

33. C. W. Lam, J. T. James, R. McCluskey, and R. L. Hunter, Toxicol. Sci. 77, 126 (2004).

34. D. B. Warheit, B. R. Laurence, K. L. Reed, D. H. Roach, G. A. M Reynolds, and T. R. Webb, Toxicol. Sci. 77, 117 (2004).

35. M. Ghovanloo and K. Najafi, A high data transfer rate frequency shift keying demodulator chip for the wireless biomedical implants, 45th Midwest Symposium on Circuits and Systems (MWSCAS'02) (2002), Vol. 3, pp. 433-436.

36. Activa RC Recharging System 37751

37. T. Akin, K. Najafi, and R. M. Bradley, IEEE Journal of Solid-State Circuits 33, 109 (1998).

38. C. Sauer, M. Stanacevic, G. Cauwenberghs, and N. Thakor, IEEE Transactions on Circuits and Systems I: Regular Papers 52, 2605 (2005).

39. B. Lenaerts and R. Puers, Biosens. Bioelectron. 22, 1390 (2007).

40. K. M. Silay, D. Dondi, L. Larcher, M. Declercq, L. Benini, Y. Leblebici, and C. Dehollain, Load optimization of an inductive power link for remote powering of biomedical implants, Proceedings of the IEEE International Symposium on Circuits and Systems 2009 (ISCAS'09) (2009), pp. 533-536.

41. M. Catrysse, B. Hermans, and R. Puers, Sens. Actuators, A: Phys. 115, 221 (2004).

42. J. Parramon, P. Doguet, D. Marin, M. Verleyssen, R. Munoz, L. Leija, and E. Valderrama, ASIC-based batteryless implantable telemetry microsystem for recording purposes, Proceedings of the 19th Annual International Conference of the IEEE Engineering in Medicine and Biology Society (1997), Vol. 5, pp. 2225-2228.

43. G. Gudnason, E. Bruun, and M. Haugland, Analog Integrated Circuits and Signal Processing 22, 81 (2000).

44. B. Smith, Z. Tang, M. W. Johnson, S. Pourmehdi, M. M. Gazdik, J. R. Buckett, and P. H. Peckham, IEEE Transactions on Biomedical Engineering 45, 463 (1998).

45. M. M. Ahmadi and G. A. Jullien, IEEE Transactions on Biomedical Circuits and Systems 3, 169 (2009).

46. A. Poon, S. O'Driscoll, and T. Meng, A mm-sized implantable power receiver with adaptative link compensation, Technical Digest of IEEE International Solid-State Circuits Conference Ser. Paper 17.5 (2009).

Received: 27 December 2010. Accepted: 14 January 2011. 